\title{
Reconocimiento automatizado de menas metálicas mediante análisis digital de imagen: un apoyo al proceso mineralúrgico. II: criterios metalogenéticos discriminantes ${ }^{(\bullet)}$
}

\author{
R. Castroviejo* y E. Berrezueta**
}

\begin{abstract}
Resumen
Demostrada la posibilidad de segmentación efectiva de menas metálicas para la automatización del estudio mineralógico mediante análisis digital de imagen sobre microscopio óptico de reflexión, se procede, ahora, a completar la metodología, integrando criterios complementarios. Se estudian las asociaciones minerales presentes en los yacimientos minerales y se comparan los valores de reflectancia correspondientes. Las posibilidades de confusión son mínimas, si se limita la selección a los componentes presentes en asociaciones reales. Se elaboran tablas con tipologías simplificadas de yacimientos y de las correspondientes asociaciones minerales, ilustrando su aplicación con ejemplos reales. En conclusión, se propone un método integrado que combina criterios físicos cuantitativos, basados en medidas fotoespectrométricas, con criterios geológicos (tipologías y asociaciones minerales). Dicho método no sustituye al experto mineralogista pero potencia, enormemente, su rendimiento y lo capacita, mediante el proceso matemático de datos digitales adquiridos una sola vez, para producir, a la carta, informaciones variadas y rápidas.
\end{abstract}

Palabras clave Menas metálicas; Análisis de Imagen; Microscopía óptica; Mineralurgia; Mineralogía.

\section{Automated microscopic characterization of metallic ores with image analysis: a key to improve ore processing. II: metallogenetic discriminating criteria}

\begin{abstract}
Ore microscopy may furnish very important information for geometallurgists, but today's needs for automation are difficult to meet with the optical microscope, unless an adequate methodology is developed. Some limitations of the routine procedure, related to risks of misidentification caused by the spectral similarity of some ores, ask for complementary criteria. Defining ore deposit typologies and the corresponding assemblages guides the choice of species and limits their number. Comparison of the reflectance values of the ores in each mineral association defined shows that their automated identification is possible in most of the common occurrences. The number of species to be actually considered being greatly limited, performance is increased. The system is not intended to substitute for a mineralogist, but to enhance enormously his performance, while offering the industry an economic procedure to produce a wealth of information which would not be possible with traditional methods, as the point counter.
\end{abstract}

Keywords

Ore mineral identification; Image analysis; Optical microscopy; Ore processing; Mineralogy.

\section{INTRODUCCIÓN}

La información mineralógica obtenida con el microscopio polarizante de reflexión ha sido, desde la puesta a punto de este instrumento, un importante apoyo para el control y mejora de los procesos mineralúrgicos. La utilización de la técnica de Análisis Digital de Imagen, ADI, como complemento de estudios de microscopía, proporciona un eficaz soporte numérico para la cuantificación de parámetros geométricos y densitométricos de los minerales, con la ventaja sobre los métodos de cuantificación clásicos, como la platina integradora sobre microscopio óptico, de su mayor versatilidad, agilidad y potencia. No obstante, el uso del ADI implica un pre-requisito: la segmentación fiable y reproducible de las menas presentes y su correspondiente identificación automatizada. En la primera parte de

\footnotetext{
(•) Trabajo recibido el día 8 de mayo de 2009 y aceptado en su forma final el día 25 de junio de 2009.

* ETSI Minas (Universidad Politécnica de Madrid, UPM), España.

** Instituto Geológico y Minero de España, IGME.
} 
este trabajo ${ }^{[1]}$ se analizaron las condiciones de preparación de muestras y de adquisición y tratamiento de imágenes requeridas por una metodología adecuada a este fin. La constatación de que las propiedades de reflectancia especular de las menas metálicas no siempre son inequívocamente diagnósticas, sino que hay algunos minerales con espectros muy próximos, obliga a investigar otro tipo de criterios complementarios cuya introducción sistemática en un sistema automatizado permita discriminar minerales de reflectancias similares y evitar posibles confusiones.

Según se concluía en el trabajo citado, es necesaria la contribución de un experto mineralogista para "la eventual introducción de posibles criterios identificativos de tipo mineralógico o metalogenético (paragénesis y asociaciones minerales), necesarios en aquellos casos en que puedan coexistir minerales con valores de reflectancia equivalentes". Ello, a pesar de la constatación de que el número de especies minerales de menas metálicas comunes en procesos mineralúrgicos es, relativamente, escaso, lo que simplifica mucho la metodología si se trata de aplicarla a problemas industriales. El objetivo de este trabajo es la definición de estos criterios, mediante dos aproximaciones complementarias: (i) la sistematización de la gran variedad de yacimientos minerales existentes, seleccionando los principales y asociándolos mediante tipologías representativas, a fin de lograr un sistema en el que su número y variedad sean manejables, sin dejar de ser un reflejo fiel de la realidad geológica; (ii) la definición de las asociaciones de minerales más comunes de cada tipo de yacimientos y, sobre todo, de aquellos minerales que, por la tipología asociada, son incompatibles y que proporcionarán criterios determinantes para su identificación automatizada. De esta forma, se imponen condiciones adicionales de validación para la identificación mineralógica realizada por el sistema y se facilita la supervisión y el control de la calidad del proceso de reconocimiento y cuantificación automatizados.

El trabajo continuado en sistemas de análisis multiespectral con técnicas de última generación recurriendo, incluso, a la obtención de valores en el dominio infrarrojo cercano (espectros VNIR, Visible and Near Infra-Red ${ }^{[2-4]}$ ), demuestra que es posible mejorar la definición de los espectros de reflectancia RGB utilizados previamente ${ }^{[1 \text { y } 5]}$. No obstante, esta mejora está limitada por la existencia o no, en los rangos medidos, de valores discriminantes en las reflectancias de los propios minerales, encontrándose, a veces, limitaciones insalvables como las que impone la similitud de espectros constatada entre hübnerita y esfalerita ${ }^{[6]}$. Por ello, la utilización de dichos criterios adicionales, de tipo geológico, conserva toda su vigencia, independientemente de cuál sea la técnica espectrométrica aplicada.
Es más, cabe pensar que habrá grupos de minerales (por ejemplo, entre las sulfosales) cuyos integrantes no van a poder ser discriminados entre sí por sus espectros de reflectancia, exclusivamente, ni siquiera con técnicas de última generación. Afortunadamente, dichos minerales suelen ser poco comunes y, por tanto, no invalidan la aplicación general a los procesos industriales, pudiendo identificarse en grupo cuando se detecta su presencia, para recurrir a técnicas microanalíticas (microsonda electrónica) si el problema lo requiere. Siempre, resultará más práctico avanzar todo lo posible con un método económico y de alto rendimiento, como el descrito, dejando las técnicas muy costosas y que exigen una elevada infraestructura, como la microsonda electrónica, para los escasos problemas que realmente las exigen. Por esta razón, también en estos casos, es de interés una reflexión sobre la aplicación de los criterios de paragénesis o de asociación mineral natural.

\section{ESTADO DEL ARTE}

Existen numerosas clasificaciones de yacimientos minerales. Su enumeración y discusión detallada rebasa el ámbito de este trabajo, pero hay que reconocer que los criterios que las presiden no siempre son objetivos o de aceptación general y ello hace que su uso haya resultado, a veces, conflictivo. Por ello, en la segunda mitad del siglo XX fueron imponiéndose tipologías caracterizadas por obedecer a criterios que reúnen, al menos, dos cualidades: a) se basan en hechos objetivos, observables sin ambigüedad por cualquier investigador; b) su definición es más descriptiva que interpretativa, es decir, se apoya en la enumeración de rasgos realmente asociados, antes que en su interpretación o en consideraciones teóricas. La tipología utilizada para este trabajo se apoya en una de reciente publicación ${ }^{[7]}$, partiendo de una clasificación genética de reconocido valor científico (la de Schneiderhoehn) ${ }^{[8]}$, actualizada de forma que resulta compatible, en general, con los criterios más avanzados actualmente, incluso los de investigación metalogenética, que atienden, ante todo, a los procesos de concentración mineral ${ }^{[9]}$. Una tipología de este tipo, necesariamente, debe dar cabida a toda clase de yacimientos minerales, incluso, algunos que actualmente han perdido interés industrial. Sin embargo, la adaptación de la misma a los objetivos de este trabajo, según se explicará oportunamente (Tabla I) prestará atención precisamente al criterio de interés industrial, aún, a costa de omitir tipos de escaso interés pero subrayando, en cambio, otros que hoy son muy relevantes como los pórfidos cupríferos o las concentraciones epitermales de oro y plata.

Por lo que respecta al objeto directo de este trabajo, la caracterización mineralógica, evidentemente, 
RECONOCIMIENTO AUTOMATIZADO DE MENAS METÁLICAS MEDIANTE ANÁLISIS DIGITAL DE IMAGEN: UN APOYO AL PROCESO MINERALÚRGICO... AUTOMATED MICROSCOPIC CHARACTERIZATION OF METALLIC ORES WITH IMAGE ANALYSIS: A KEY TO IMPROVE ORE PROCESSING...

Tabla I. Selección de clases principales de yacimientos minerales, por su tipología y contenido metálico

Table I. Selection of main classes of ore deposits, based on deposit typology and ore composition

\section{AMBITO MAGMÁTICO}

1. En rocas ultramáficas y complejos ofiolíticos (Cr, EGP, Ni, Cu, Fe-Ti)

1.1 Cromitita / Cromitita podiforme (ofiolítica)

1.2 Óxidos $\mathrm{Fe}-\mathrm{Ti}$

1.3 EGP (Elementos del Grupo del Platino)

1.4 Sulfuros Ni-Cu (cf. R. máficas, §2.1). SMV ofiolíticos (cf. §8.1)

2. En rocas máficas $(\mathrm{Ni}, \mathrm{Cu}, \mathrm{Fe}, \mathrm{Ti}, \mathrm{EGP})$.

2.1 Sulfuros $\mathrm{Ni}-\mathrm{Cu}( \pm \mathrm{EGP})$

2.2 Óxidos $\mathrm{Fe}-\mathrm{Ti}$ (cf. Rocas ultramáficas § 1.3)

3. Pegmatítico - Neumatolíticos (Sn, W, Nb-Ta, Au...)

\section{AMBITO HIDROTERMAL}

4. Filones Hidrotermales y Mantos

4.1 Filones $\mathrm{Pb}-\mathrm{Zn}-\mathrm{Ag}$ y otros.

5. Pórfidos $(\mathrm{Cu}, \mathrm{Mo}, \mathrm{Au})$

5.1 Pórfido de $\mathrm{Cu}$ y $\mathrm{Cu}-\mathrm{Au}$

5.2 Pórfido de Mo y Cu-Mo

6. Epitermales (Ag, $\mathrm{Au}, \mathrm{Pb}, \mathrm{Zn}, \mathrm{Cu})$

6.1 Alta Sulfuración.

6.2 Baja Sulfuración.

7. Diseminaciones tipo Carlin (Au)

\section{AMBITO SEDIMENTARIO}

8. Depósitos volcano-sedimentarios. Formaciones bandeadas $\mathrm{Fe} / \mathrm{Mn}$

8.1 Sulfuros Masivos Volcanogénicos (SMV: $\mathrm{Cu}, \mathrm{Pb}, \mathrm{Zn}, \mathrm{Ag}, \mathrm{Au}$ )

8.2 Formaciones Bandeadas de Hierro (BIF) y de Mn (BMF)

9. Yacimientos $\mathrm{Cu}-\mathrm{Pb}-\mathrm{Zn}$ en rocas sedimentarias

9.1 Tipos SEDEX y Mississippi Valley (Pb, Zn, Ag)

9.2 Tipos Kupferschiefer / Copperbelt (Cu y polimetálicos)

10. Detríticos y residuales

10.1 Placeres, paleoplaceres, meta-conglomerado (Au, Sn, W, U, etc.)

10.2 Lateritas (Ni, Al)

\section{AMBITO METAMÓRFICO}

11. Skarn (Cu, Zn, Au, Sn, W, Ag...)

12. En greenstone belts y terrenos metamórficos (Au, $\mathrm{Cu}, \mathrm{Zn}, \mathrm{Fe}, \mathrm{Mn} . .$.

12.1 Yac. oro orogénicos o ligados a zonas de cizalla $(\mathrm{Au})$

12.2 Yac. metamorfizados: SMV, SEDEX, BIF / Itabiritas $(\S 8,9)$

tiene una relación reconocida con la tipología del yacimiento. Si bien, existen minerales como la pirita que son comunes a gran número de tipos, generalmente, los autores distinguen las asociaciones minerales características de las distintas clases. El uso del término "asociación mineral" (mineral association) puede ser ambiguo y debe precisarse. Habitualmente, se refiere al conjunto de minerales realmente presentes en una muestra o, por extensión, en una roca, yacimiento o clase de yacimientos. Se contrapone al concepto más restringido de "paragénesis" (assemblage, término indebidamente traducido a veces por "ensamble"), el cual se refiere, exclusivamente, a los minerales formados en equilibrio, al mismo tiempo y por un mismo 
episodio genético (algunos autores son incluso más exigentes y requieren la evidencia de contacto físico entre los minerales para garantizar las condiciones de equilibrio) $)^{[10]}$.

Sin embargo, en la literatura se confunde, a veces, el uso de ambos términos, de lo que puede resultar cierta confusión, aunque basta recurrir a un simple caso práctico para exponer los conceptos más allá de cualquier ambigüedad. Si se piensa, por ejemplo, en un pórfido cuprífero, la mineralización económica suele resultar de la combinación de varios procesos sucesivos, algunos, magmático-hidrotermales, otros, supergénicos. Así la alteración potásica suele ir acompañada de la precipitación de biotita, feldespato potásico, calcopirita, pirita, etc., minerales que definen una paragénesis de mena primaria (suele designarse por el nombre de la alteración, potásica, asociada); posteriormente, los procesos de meteorización actúan sobre las partes expuestas del yacimiento, lixivian el cobre y lo reprecipitan en profundidad, en condiciones reductoras, formando minerales como calcosina, digenita, covellina..., que constituyen otra paragénesis, en este caso, de mena secundaria (cementativa), la cual suele suponer un incremento sustantivo del contenido metálico. El minero que extrae la mineralización de la zona de cementación puede encontrarse minerales primarios relictos (por ejemplo, de la paragénesis potásica), parcialmente reemplazados por minerales secundarios neoformados (por ejemplo, de la paragénesis cementativa). Todos ellos, en conjunto, constituyen la asociación mineral que el metalurgista va a procesar en la planta de concentración de la mina.

En principio, podría parecer más riguroso, desde el punto de vista metalogenético, hablar de paragénesis para caracterizar un yacimiento mineral y los distintos episodios que lo han generado. No obstante, para este trabajo, se ha optado por hablar de asociaciones minerales, ya que son el objeto real que tanto el metalurgista como el microscopista que pretenda apoyarlo se van a encontrar finalmente. Se hará, pues, el ejercicio de integrar la mineralogía de las asociaciones reales, aunque sean poligenéticas y aunque haya que sumar diferentes paragénesis, con la única condición de que se correspondan a la realidad geológica. De esta forma, se espera facilitar al metalurgista una herramienta más útil y evitar confusiones.

\section{METODOLOGÍA}

La optimización de criterios y métodos para la identificación de menas metálicas con microscopio óptico es, todavía, objeto de investigación ${ }^{[11]}$. A pesar de la existencia de excelentes monografías ${ }^{[12-19]}$ y de las correspondientes actualizaciones por parte de IMA/COM (Commission on Ore Mineralogy, International
Mineralogical Association) $)^{[20-22]}$, la metodología es poco conocida, debido a la escasa presencia de la materia en los planes de estudios habituales de Ciencias de la Tierra, lo que puede conducir a una fuerte carencia de especialistas en un futuro próximo. Esto, hace también más apremiante la elaboración de metodologías alternativas. La reciente disponibilidad de técnicas capaces de medir las reflectancias espectrales con gran precisión y rapidez (intervalos de $m s$ a s) permite pensar en un proceso automatizado, aunque no en la sustitución total del experto mineralogista, sino en la potenciación de su trabajo y en el incremento de su rendimiento, al liberarlo de tareas rutinarias como el análisis modal mediante el contador de puntos o platina integradora. Para un uso adecuado, es imprescindible ser consciente de las limitaciones metodológicas de la automatización. Las medidas espectrales pueden descartar automáticamente los minerales que, en condiciones standard garantizadas (calidad de pulido, iluminación...), no corresponden a los valores medidos, pero no pueden decidir entre dos minerales con valores espectrales equivalentes a no ser que se introduzcan otros criterios discriminantes. Los criterios de tipología y asociación mineral son una clave muy importante al respecto.

\subsection{Minerales comunes}

Otra clave esencial está implícita en el planteamiento adecuado del problema. El reducir a un mínimo razonable el número de especies a considerar desde el principio es de una considerable importancia práctica, pues introduce un primer filtro decisivo para la información a analizar y evita una sobrecarga del sistema que sólo podría restarle eficacia. Las menas metálicas definidas superan hoy el millar. No obstante, hay un consenso basado en la experiencia ${ }^{[11 \text { y } 23]}$ que reduce a una pequeña fracción (en torno a unas treinta) las especies habituales, cifra que se restringe todavía más si se refiere a las de interés industrial.

Una metodología general de aplicación a problemas industriales debe centrarse, en primer lugar, en este pequeño grupo, cuya selección ya se justificó anteriormente ${ }^{[1 \text { y } 5]}$ y que constituirá la base de datos experimental de referencia. Ulteriormente, para problemas específicos que impliquen una mineralogía singular, pueden ampliarse las opciones añadiendo las especies pertinentes.

Por esta razón, se plantea una selección de minerales (Tablas II, III y IV), de más a menos comunes entre las menas metálicas, estructurada en módulos de uso progresivamente más específico o restringido: el primer grupo (Tabla II) es el que contiene el núcleo de los minerales de uso habitual, el único que va a usarse normalmente; el segundo (Tabla III) comprende minerales que esporádicamente pueden tener interés, como el grafito, que puede presentarse 
ocasionalmente en asociaciones en las que no necesariamente es un mineral tipológico (por ejemplo, en yacimientos orogénicos de oro); o el complejo grupo de las sulfosales de plata, de las que sólo se han reseñado algunas más comunes y que no se identifican fácilmente al microscopio por sus propiedades cualita- tivas ni por su reflectancia especular, aunque sí pueden discriminarse como grupo y cuantificarse por ADI, si se evita la rápida alteración superficial o "ataque por luz" típico de algunas especies, como argentita o polibasita; finalmente, el tercer grupo (Tabla IV) reúne especies que no son habituales, si bien pueden llegar

Tabla II. Minerales más frecuentes en menas comunes

Table II. Most frequent minerals in common ores

\begin{tabular}{|c|c|c|c|}
\hline CLASE & MINERAL & símBOLO & OBSERVACIONES \\
\hline Elementos & $\begin{array}{l}\text { Oro nativo } \\
\text { Plata nativa } \\
\text { Platino nativo }\end{array}$ & $\begin{array}{l}\mathrm{Au} \\
\mathrm{Ag} \\
\mathrm{Pt}\end{array}$ & \\
\hline $\begin{array}{l}\text { Sulfuros / } \\
\text { Arseniuros }\end{array}$ & $\begin{array}{l}\text { Argentita/Acantita } \\
\text { Arsenopirita } \\
\text { Bismutina } \\
\text { Bornita } \\
\text { Calcopirita } \\
\text { Calcocita } \\
\text { Cinabrio } \\
\text { Covellina } \\
\text { Cubanita } \\
\text { Digenita } \\
\text { Esfalerita } \\
\text { Enargita } \\
\text { Estibina } \\
\text { Galena } \\
\text { Linneita } \\
\text { Marcasita } \\
\text { Molibdenita } \\
\text { Niquelina } \\
\text { Pentlandita } \\
\text { Pirita } \\
\text { Pirrotita }\end{array}$ & $\begin{array}{l}\text { arg/ac } \\
\text { asp } \\
\text { bm } \\
\text { bn } \\
\text { ccp } \\
\text { cct } \\
\text { cin } \\
\text { cV } \\
\text { cn } \\
\text { dig } \\
\text { sp } \\
\text { en } \\
\text { stib } \\
\text { gn } \\
\text { In } \\
\text { mar } \\
\text { mo } \\
\text { nc } \\
\text { pn } \\
\text { py } \\
\text { po }\end{array}$ & Sinónimo calcosina \\
\hline Sulfosales & Tetrahedrita & thd & Serie isomorfa \\
\hline $\begin{array}{l}\text { Óxidos, } \\
\text { hidróxidos, } \\
\text { tungstatos, } \\
\text { etc. }\end{array}$ & $\begin{array}{l}\text { Casiterita } \\
\text { Cromita } \\
\text { Cuprita } \\
\text { Goethita } \\
\text { Hematites } \\
\text { Ilmenita } \\
\text { Magnetita } \\
\text { Pirolusita } \\
\text { Psilomelana } \\
\text { Rutilo } \\
\text { Uraninita } \\
\text { Wolframita }\end{array}$ & $\begin{array}{l}\text { cs } \\
\text { cr } \\
\text { cup } \\
\text { goe } \\
\text { ht } \\
\text { il } \\
\text { mg } \\
\text { prl } \\
\text { psi } \\
\text { ru } \\
\text { uran } \\
\text { wf }\end{array}$ & $\begin{array}{l}\text { Ver paragénesis } \\
\text { Ver paragénesis } \\
\text { Asociación limonita } \\
\text { Asociación limonita } \\
\text { Ver paragénesis } \\
\text { Ver paragénesis } \\
\text { Ver paragénesis } \\
\text { Ver paragénesis } \\
\text { Ver paragénesis }\end{array}$ \\
\hline Ganga & $\begin{array}{l}\text { Cuarzo } \\
\text { Carbonatos } \\
\text { Mins. Arcillosos }\end{array}$ & $\begin{array}{l}\text { q } \\
\text { Carb } \\
\text { MArc }\end{array}$ & $\begin{array}{l}\text { Ver paragénesis } \\
\text { Ver paragénesis } \\
\text { Ver paragénesis }\end{array}$ \\
\hline
\end{tabular}


Tabla III. Minerales con paragénesis peculiares

Table III. Minerals with particular paragenesis

\begin{tabular}{|c|c|c|c|}
\hline CLASE & MINERAL & SíMBOLO & OBSERVACIONES \\
\hline Elementos & Grafito & gra & \\
\hline & $\begin{array}{l}\text { Cobaltina } \\
\text { Eskutterudita } \\
\text { Estannita }\end{array}$ & $\begin{array}{l}\text { cob } \\
\text { sk } \\
\text { stan }\end{array}$ & $\begin{array}{l}\text { Ver paragénesis } \\
\text { Ver paragénesis }\end{array}$ \\
\hline Sulfuros y & Gersdorffita & gf & Ver paragénesis \\
\hline \multirow[t]{4}{*}{ Sulfosales } & Miargirita & my & Ver paragénesis \\
\hline & Pearceita-Polibasita & pc-plb & Ver paragénesis \\
\hline & Pirargirita-Proustita & pr-pu & Ver paragénesis \\
\hline & Rammelsbergita & $\mathrm{rm}$ & Ver paragénesis \\
\hline Óxidos & Lepidocrocita & Ip & Ver paragénesis \\
\hline
\end{tabular}

Tabla IV. Minerales de interés restringido

Table IV. Minerals of limited interest

\begin{tabular}{llll}
\hline CLASE & MINERAL & SímBOLO & OBSERVACIONES \\
\hline Elementos & Allemontita & alle & $\begin{array}{l}\text { Asoc. Ag, As y Sb nat. } \\
\text { Inestable }\end{array}$ \\
& Antimonio nat. & $\mathrm{Sb}$ & Asoc. Ag y As nativos. \\
& Bismuto nativo & $\mathrm{Bi}$ & Ver paragénesis \\
& Cobre nativo & $\mathrm{Cu}$ & Ver paragénesis \\
& Electrum & $\mathrm{el}$ & Ver Ag, Au \\
& Estibarsénico & $\mathrm{SbAs}$ & Sinónimo de allemontita \\
\hline \multirow{4}{*}{ Sulfuros y y } & Boulangerita & $\mathrm{bl}$ & Ver paragénesis \\
& Bournonita & $\mathrm{bo}$ & Ver paragénesis \\
& Jamesonita & $\mathrm{jm}$ & Ver paragénesis \\
& Loellingita & $\mathrm{lo}$ & Ver paragénesis \\
& Luzonita & $\mathrm{l}$ & Serie isomorfa con famatinita \\
& Maucherita & $\mathrm{mau}$ & Ver paragénesis \\
& Millerita & $\mathrm{ml}$ & Ver paragénesis \\
Varios & Ullmanita & $\mathrm{ul}$ & Ver paragénesis \\
& Mins. Gr. Pt & $\mathrm{MGP}$ & Mineralogía muy específica \\
& Minerales $\mathrm{U}$ & $\mathrm{MU}$ & Mineralogía muy específica \\
\hline
\end{tabular}

a tener importancia en ámbitos restringidos y requerir el desarrollo de metodologías específicas.

En suma, se considera como la selección fundamental de minerales para su identificación espectrofotométrica la contenida en el primer grupo (Tabla II). Es verdad que en algunas mineralizaciones o tipos de yacimientos la mineralogía es más compleja y variada y así ocurre en yacimientos como Uchuchaccua (Perú) o, en general (Tabla IV), en tipos como los de "cinco elementos" (Ni-Co-Bi-Ag-U), los de tierras raras o los de elementos del grupo del platino, EGP. Pero, esto, no invalida cuanto acaba de decirse, pues estos casos son muy específicos o locales y requieren una metodología ad hoc que no puede considerarse como de aplicación general, por razones obvias de coste y rendimiento, cosa que por otra parte suele ocurrir, también, con su analítica, con su mineralogía (no del todo conocida todavía) y con su metalurgia: los MGP, minerales del grupo del platino, se estudian normalmente con apoyo microanalítico 
(microsonda electrónica, microscopio electrónico equipado con sistema de barrido y ADI adaptado, Qemscan, etc.).

Estas consideraciones son también de aplicación a otras propuestas algo más complejas, como la presentada por L. Robb ${ }^{[9]}$ para los "minerales comunes de mena y ganga", que se plasma en una relación de 108 especies. De ellas, más de la mitad (56) corresponden a minerales transparentes (habitualmente ganga) y, por tanto, ajenos al objetivo de este trabajo, al no ser susceptibles de determinación correcta por reflectometría. La relación de menas susceptibles de estudio con luz reflejada comprende 52 especies minerales, sistematizadas en las clases Elementos (Metales / No metales), Sulfuros y Sulfosales, Óxidos e Hidróxidos, Oxisales. El análisis pormenorizado de esta relación revela que en este conjunto hay 19 especies poco frecuentes que deberían omitirse, pues suponen una sobrecarga sin valor añadido para una relación de tipo general. Estas 19 especies son:

- entre los metales, 2 especies: paladio y cobre, nativos; al primero, por ser específico de yacimientos EGP, le es de aplicación lo que se ha dicho para este tipo de concentraciones, aparte de que la presencia del platino nativo, muy próximo al paladio en sus propiedades de reflectancia, permitiría detectar, en un primer momento, la posibilidad de esta mineralogía; el segundo, es muy restringido (por ejemplo en Superior, USA) y no puede considerarse como una mena común de cobre, aparte de que su caracterización espectrofotométrica es relativamente sencilla;

- entre los sulfuros y sulfosales, 12 especies: millerita, eskutterudita, sperrylita, braggita / cooperita, moncheita, rejalgar, oro pimente, calaverita y laurita, a las cuales se puede aplicar lo ya dicho para los MGP (sperrylita, braggita / cooperita, moncheita, laurita) o, en el caso de millerita y eskutterudita, para los grupos de la tablas III y IV, mientras que rejalgar y oro pimente se asimilan, por sus propiedades ópticas, más bien a la ganga y, finalmente, calaverita $\left(\mathrm{AuTe}_{2}\right)$ es un mineral muy poco frecuente cuya cuantificación habría de plantearse más bien como la de los MGP (MEB con análisis de imagen); por otra parte, en la serie de los cobres grises resulta redundante considerar los dos términos (tetrahedrita tennantita) si de lo que se trata es de su identificación espectrofotométria ya que, en rigor, no van a poder distinguirse ópticamente $y$, por tanto, bastará considerar un solo "mineral" como representante de la serie; probablemente, tampoco se encontrarán habitualmente cobaltina, gersdorffita y loellingita, excepto en paragénesis singulares (Tablas III y IV), sin embargo, se echa de menos en esta relación la presencia de arsenopirita, mineral relativamente extendido, aunque pocas veces abundante y que, en la relación propuesta, sí se ha incluído en el grupo principal (Tabla II);

- entre los óxidos e hidróxidos, 5 especies: hercynita, gahnita, anatasa, thorianita y columbita-tantalita; las razones son las siguientes: a las espinelas hercynita y gahnita, que no son precisamente minerales habituales en rocas o yacimientos comunes, puede aplicarse el mismo razonamiento que a los cobres grises, con el dato adicional de que ya hay dos miembros del grupo que sí se analizan (cromita y magnetita); la anatasa tampoco es mena común y, ópticamente, es análoga al rutilo, incluído en la lista; finalmente, la thorianita y la columbita-tantalita, sí tienen importancia económica pero aparecen en ámbitos muy restringidos;

- entre las 20 oxisales citadas por L. Robb ${ }^{[9]}$, se ha considerado (Tabla II), únicamente, la wolframita, ya que todas las demás se reconocen, preferentemente, con luz transmitida; no obstante, en casos singulares, podrían añadirse minerales como scheelita, siderita, azurita, malaquita o cerusita, si el estudio mineralógico previo detectase su presencia pues, aunque sean minerales transparentes, su reflectancia, con luz reflejada, es superior a la de la ganga y puede cuantificarse.

Teniendo en cuenta estos criterios, también la cifra real de menas comprendidas en la propuesta de Robb $^{[9]}$, una vez depurada de minerales exóticos o muy específicos, se reduce a 33 especies y, en conjunto, resulta una propuesta análoga a la elaborada para este trabajo (38 minerales, sin contar los de ganga: Tabla II).

Lo mismo puede decirse de otras selecciones. Así, la realizada por T. Febrel ${ }^{[19]}$, con fines didácticos más que de aplicación industrial, comprende 50 "minerales opacos", entre los que se cuentan algunos de interés marginal o incluso, hoy día, no reconocidos por COM / IMA (bravoita, calcopirrotina). Para los objetivos de este trabajo y en aplicación de los criterios expuestos, pueden apartarse, por ejemplo, valleriita, jordisita, villamaninita, safflorita, maghemita, cobre nativo, arsénico nativo, bismuto nativo, millerita, cobaltina, eskutterudita, proustita, pirargirita, mirargirita, pearceita, polibasita, aparte de los dos desacreditados por IMA/COM ya mencionados. En total, se descartan 18 "minerales opacos", lo que reduciría a 32 el número de especies a considerar, dejando abierta la posibilidad de contemplar, eventualmente, algún mineral adicional, si la singularidad de un yacimiento lo requiriese.

En todo caso, es importante tener en cuenta que no debe ser el ordenador el que decide la identidad de 
un mineral sino el mineralogista ${ }^{[22]}$ : es éste el que puede tener en mente todos los minerales posibles y el que decide, auxiliado por el ordenador, descartar aquéllos cuyas propiedades no corresponden a los datos objetivos. O bien, comprobar críticamente la realidad de datos inesperados, lo que puede implicar ya sea la posible existencia de una mineralogía extraordinaria (no puede excluirse a priori la posibilidad de asociaciones excepcionales), ya la decisión de revisar medidas anómalas. Al respecto, procede analizar la realidad geológica de partida de las concentraciones minerales: tipología de yacimientos y asociaciones mineralógicas correspondientes.

\subsection{Tipologia de yacimientos $y$ asociaciones minerales}

El proceso de sistematización operado para clasificar las rocas comunes puede servir de ejemplo para explicar el propuesto en este trabajo para la mineralogía de las menas metálicas.

La gran variedad posible en las composiciones mineralógicas de las rocas que constituyen la corteza terrestre ha sido reducida por los petrólogos, con criterios lógicos y realistas, a un sistema muy simple: se ha hablado primero de minerales formadores de rocas comunes y luego de una clasificación sistemática de éstas, apoyada en un número muy limitado de minerales. Así, por ejemplo, para las rocas ígneas es prácticamente unánime la aceptación de la propuesta de la IUGS (Internacional Union of Geological Sciences) ${ }^{[24]}$, basada en la mayor parte de los casos en tres minerales o grupos de minerales: cuarzo, feldespatos (alcalinos y plagioclasas) y feldespatoides; en el caso de rocas ultramáficas, se consideran además piroxenos, hornblenda y olivino. En casos particulares (por ejemplo, lamprófidos o carbonatitas), puede recurrirse a otros minerales, en número siempre muy limitado. En conjunto, la mineralogía fundamental para la clasificación de rocas ígneas se limita a unos 10 a 15 minerales o grupos de minerales, los cuales definen las asociaciones que, por su naturaleza y proporciones relativas, identifican los distintos tipos.

Por lo que respecta a las menas metálicas, aunque pueden clasificarse por su composición mineralógica, no es éste el enfoque más eficaz para su caracterización: se acepta, más bien, como punto de partida, la clasificación o tipología de yacimientos, que comprende criterios como el contexto geológico, morfología, génesis, procesos preferentes de concentración, alteraciones, etc. Aun así, si se analizan con criterios cuantitativos las composiciones mineralógicas de cada tipo, se constata que son relativamente escasos los minerales abundantes, muchos de los cuales se repiten en diferentes tipos.
Existen diversas recopilaciones de yacimientos minerales con información mineralógica, desde las menos sistemáticas o las más específicas ${ }^{[13,25}$ y 26$]$ has-

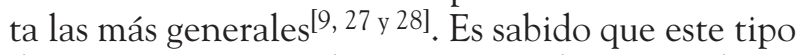
de información puede ser una ayuda muy útil, incluso, para la identificación de un mineral desconocido, como hace notar D. Vaughan ${ }^{[29]}$ : "a mineral most commonly occurs in nature as a part of an assemblage, and this association itself is of considerable value in identification, because there are numerous examples of characteristic assemblages".

Para los fines de este trabajo y en consonancia con lo expuesto al comienzo del presente apartado, interesa una clasificación sistemática, basada en una tipología general como la presentada en la Tabla I, lo más simplificada posible y de fácil acceso para el no especialista, es decir, que no requiera conceptos excesivamente especializados para su uso y que sea, por tanto, asequible para el profesional de la Geometalurgia, no necesariamente versado en Ciencias de la Tierra. Se priorizará, por tanto, el uso de términos mineros bien establecidos, como "pórfido cuprífero", "sulfuros masivos" o "yacimientos epitermales". Y se evitarán, en lo posible, terminologías ambiguas o la duplicidad contradictoria de criterios que se encuentran en algunos tratados. Esto ocurre, por ejemplo, en la propuesta de P.R. Ineson $^{[26]}$ con el yacimiento de Río Tinto, en la Faja Pirítica Ibérica, citado simultáneamente como Copper \pm Zinc-Iron-Silver / Zinc \pm Copper-Iron / ZincLead \pm Copper-Iron y como Copper-Molybdenum associated with porphyry intrusive igneous rocks / i.e. the Porphyry Copper-Molybdenum deposits, lo que es comprensible teóricamente, hasta cierto punto, si se tiene en cuenta que este gran yacimiento comprende sulfuros masivos estratiformes singenéticos y una zona de raíz o stockwork epigenética y ligada a un pórfido riolítico, pero resulta inadecuado porque: (i) el pórfido de Río Tinto es parte del sistema normal de los sulfuros masivos volcanogénicos y no tiene nada que ver con la composición habitual ni con el entorno conocido de los pórfidos cupríferos; (ii) una tal duplicidad induce a confusión al usuario poco informado.

La opción que se considera más razonable (Tabla I) parte de 12 tipos indispensables por su importancia mundial, subdivididos en 19 clases, pero se concibe como una base de datos abierta en la que el usuario, en la medida de sus necesidades y de la información que vaya adquiriendo, puede introducir más tipos y asociaciones minerales. Debe decirse claramente que la información hoy disponible no sólo no permite una definición cerrada, invariable y absolutamente precisa de la mineralogía de cada clase de yacimientos sino que, más bien, sugiere que nunca será posible tal pretensión. Esto no invalida el objetivo de definir las regularidades que rigen la composición mineralógica y que constituyen una 
gran ayuda para la identificación de las especies presentes, pero sí desacredita cualquier aplicación dogmática. Es preferible dejar un sistema transparente y abierto para un aprendizaje continuo, que pretender un sistema acabado y complejo que no puede hacer justicia a la realidad y sólo podría inducir a error, pues en definitiva todavía queda mucho por descubrir de los yacimientos minerales.

Ahora, es preciso sintetizar la información mineralógica correspondiente a las clases de la tabla I, de forma que sea utilizable para los fines planteados. Para ello se ha elaborado la tabla V, a partir de datos bibliográficos ${ }^{[25-31]}$ y de la propia experiencia, teniendo en cuenta que la información que interesa al metalurgista es la asociación mineralógica real que se va a encontrar. Esto, significa que, por ejemplo, en un pórfido cuprífero hay que considerar los sucesivos procesos que intervienen y sus correspondientes paragénesis (mineralizaciones primarias y posibles efectos superpuestos de alteración, lixiviación o enriquecimiento supergénico), que pueden encontrarse o no expresadas en la muestra a estudiar; por ello, la mineralogía consignada, aun siendo la más característica, no siempre se va a encontrar completa en todas las muestras: los minerales realmente presentes dependen de los procesos que hayan actuado en la porción del yacimiento considerada. En cada caso se distinguen los minerales más abundantes o importantes (principales) y los accesorios, pero se debe tener en cuenta que esta distinción no es puramente cuantitativa, como suele hacerse en petrografía (principales: $\geq 5$ $\%$ contenido modal; accesorios: $<5 \%$ contenido modal), sino práctica y cualitativa, referida no sólo a la cantidad sino al interés económico del metal en cuestión (se ha de tener en cuenta, también, que las proporciones relativas de los minerales presentes en un yacimiento pueden variar ampliamente en el espacio; por tanto, las proporciones observadas al microscopio dependen de la representatividad de la muestra o, en general, de la calidad y objetivos del muestreo). En esta acepción, son designados como "minerales principales" no sólo los abundantes sino también aquéllos que aunque escasos, como el oro o los EGP presentes a nivel de ppm, son susceptibles de aprovechamiento industrial. Los "accesorios" son siempre minerales escasos. Finalmente, dado el objetivo de este trabajo, la atención se centra esencialmente en las menas metálicas y no se entra, habitualmente, en detalles acerca de la composición de la ganga, cuyas técnicas de estudio (microscopía de transmisión con luz polarizada) difieren de las aquí consideradas. Como ejemplo, las figuras 1 y 2 (fotomicrografías F1 a F10) ilustran el aspecto al microscopio de algunas asociaciones características, para las que se indica, en cada caso, la mineralogía de la mena y la tipología del yacimiento.

\section{ENSAYOS DE APLICACIÓN}

La pertinencia de esta metodología se va a poner a prueba a través de su aplicación a varios ejemplos concretos, que permitirán valorar y discutir las posibilidades de discriminación en casos reales, anticiparse a los problemas mediante una estimación previa de las incertidumbres posibles y depurar la metodología.

\subsection{Sistemática de reconocimiento. Criterios de discriminación}

En general, cualquier proceso de identificación (los automatizados también) se basa en la discriminación entre los minerales que corresponden o no a las propiedades observadas y se enfrenta a limitaciones y exigencias ${ }^{[22]}$ que hay que tener en cuenta para lograr resultados correctos. Estos requisitos podrían resumirse así:

- Todos los minerales conocidos deben ser tenidos en cuenta, si se procede a una identificación teóricamente aplicable, en abstracto, a cualquier muestra; sin embargo, las descripciones habituales de minerales de menas son limitadas (habitualmente, del orden del centenar de especies, entre 100 y 350), lo que significa que el mineralogista identifica el mineral problema nombrando aquél cuyas propiedades encajan mejor en sus observaciones pero, al elegirlo a partir de una lista restringida, no sabe si hay otros minerales (ajenos a la lista) que puedan mostrar propiedades similares o incluso más próximas.

- Si se considera la totalidad de los minerales conocidos (por encima del millar, sólo entre los minerales metálicos), es importante que la aplicación de los principales criterios de selección reduzca las opciones a un número mínimo.

- Es esencial que, en el proceso de identificación, el mineral correcto no sea eliminado de estas opciones, lo que exige cierta tolerancia inicial en la aplicación de los criterios de selección, teniendo en cuenta las posibilidades de error en las medidas, o de peculiaridades como orientación, variaciones composicionales, calidad del pulido, etc. que condicionan las observaciones. Esta necesidad de tolerancia inicial conduce al manejo de una lista de posibilidades amplia, en contradicción con la exigencia anterior de reducir las opciones a un mínimo. Se requiere, por tanto, la aplicación de filtros adicionales mediante la aplicación de criterios alternativos.

- Para la formulación y aplicación de estos criterios es de gran importancia la experiencia del observador, que puede ser auxiliada (pero no sustituída) por técnicas informatizadas. 
Tabla V. Asociaciónes mineralógicas (menas más frecuentes) correspondientes a las clases de yacimientos de la Tipología simplificada (Tabla I)

Table V. Mineral Associations (most common ores) related to selected deposit types (Table I)

\begin{tabular}{|c|c|c|c|c|c|}
\hline \multirow[t]{2}{*}{ TIPO DE YACIMIENTO } & \multirow[t]{2}{*}{$\begin{array}{l}\text { CLASE } \\
\text { (Tab.I) }\end{array}$} & $\begin{array}{l}\text { ASOCIACIONES } \\
\text { (MENAS*) }\end{array}$ & MINERALES & \multirow[t]{2}{*}{ EJEMPLOS } & \multirow[t]{2}{*}{ OBSERVACIONES $\left({ }^{* *}\right)$} \\
\hline & & Mins Principales & Mins Accesorios & & \\
\hline Cromitita & 1.1 & $\begin{array}{l}\mathrm{cr}( \pm \mathrm{mg} / \mathrm{spin}, \mathrm{il}) \\
\text { silicatos }\end{array}$ & $\begin{array}{l}\text { MGP (Mins. Gr., } \\
\text { Pt), sulfuros }\end{array}$ & $\begin{array}{l}\text { Bushveld (RSA), Moa } \\
\text { (Cuba) }\end{array}$ & $\begin{array}{l}\text { Presencia EGP posible, pero } \\
\text { muy restringida (F 4) }\end{array}$ \\
\hline Platino o EGP & 1.3 & $\begin{array}{l}\text { MGP (Mins. del } \\
\text { Grupo del Pt) }\end{array}$ & - & Merensky Reef (RSA) & Mineralogía excepcional (F 7) \\
\hline $\begin{array}{l}\text { Sulfuros de } \mathrm{Ni}-\mathrm{Cu} \\
\text { asociados a } \\
\text { ultramafitas }\end{array}$ & $1.4 \mathrm{a}$ & $\begin{array}{l}\text { po, pn, py, ccp, } \\
\text { mg, Fe_cr }\end{array}$ & ml / Sulf. Ni / Co & Kambalda, Australia & Subclase Sulf. Ni-Cu (F 4) \\
\hline $\begin{array}{l}\text { Sulfuros masivos tipo } \\
\mathrm{Cu}(\mathrm{Zn})\end{array}$ & $1.4 \mathrm{~b}$ & py, ccp, Au & \multicolumn{2}{|c|}{$\begin{array}{l}\text { sp, po, cc, cv, mg, Chipre } \\
\text { ht, goe }\end{array}$} & $\begin{array}{l}\text { Subclase SMV ofiolít. Au sólo } \\
\text { ocasional }\end{array}$ \\
\hline $\begin{array}{l}\text { Sulfuros de Ni-Cu } \\
\text { asociados a gabros }\end{array}$ & 2.1 & $\begin{array}{l}\text { po, pn, py, mg, } \\
\text { cсp }\end{array}$ & $\mathrm{cn}, \mathrm{MGP}, \mathrm{nc}, \mathrm{ml}$ & $\begin{array}{l}\text { Sudbury(Canadá), } \\
\text { Norilsk (Rusia) }\end{array}$ & MGP ocasionales \\
\hline Titano-mg & 2.2 & mg, il, ht, ru & Po, ccp, py & $\begin{array}{l}\text { Allard Lake (Québec, } \\
\text { Canadá) }\end{array}$ & Similares clase 1.2 \\
\hline $\begin{array}{l}\text { Pegmatíticos y } \\
\text { neumat.-hidrotermales }\end{array}$ & 3.1 y 3.2 & cs, wf, py, asp & mo, po, ccp, stan & $\begin{array}{l}\text { Kalima (R.D. Congo) } \\
\text { Erzgebirge (Alemania), } \\
\text { Cornwall (UK) }\end{array}$ & $\begin{array}{l}\text { Mineralogía muy variada } \\
\text { (pegmatitas) ( } F 9 \text { y } 10)\end{array}$ \\
\hline $\begin{array}{l}\text { Filones } \mathrm{Pb}-\mathrm{Zn} \text { - Ag. } \\
\text { Mantos íd. }\end{array}$ & 4.1 & $\begin{array}{l}\text { py, sp, gn, ccp, } \\
\text { thd }\end{array}$ & $\begin{array}{l}\text { Ag nativa, bn, cc, } \\
\mathrm{cv} \text {, sulfosales }\end{array}$ & $\begin{array}{l}\text { Linares (España), } \\
\text { Coeur d'Alène (EE. } \\
\text { UU.) }\end{array}$ & $\begin{array}{l}\text { Mineralogía puede ser } \\
\text { variada; sulfosales de Ag (F 1, } \\
\text { 3 y 8) }\end{array}$ \\
\hline $\begin{array}{l}\text { Pórfidos cupríferos } \\
\text { (Cu- Au y Cu-Mo) }\end{array}$ & $5.1 / 5.2$ & $\begin{array}{l}\text { py, ccp, mo, bn, } \\
\text { cc, cv, dig, } \\
\text { sulfosales }\end{array}$ & $\begin{array}{l}\text { mg, ht, enargita, } \\
\text { cn, il, ru, Au y Ag } \\
\text { nativos, goe }\end{array}$ & $\begin{array}{l}\text { Chuquicamata (Chile) / } \\
\text { Toquepala (Perú) }\end{array}$ & $\begin{array}{l}\text { Asoc. minerales hipo- y } \\
\text { supergénicos, importante } \\
\text { enriquecimiento secundario }\end{array}$ \\
\hline $\begin{array}{l}\text { Epitermales de alta } \\
\text { sulfuración }\end{array}$ & 6.1 & $\begin{array}{l}A u \pm A g, p y, c c p \\
\text { en }\end{array}$ & $\mathrm{cv}, \mathrm{sp}$, gn, gth & $\begin{array}{l}\text { Yanacocha (Perú) } \\
\text { Rodalquilar (Almería) }\end{array}$ & $\begin{array}{l}\text { Tipo cuarzo-alunítico o ácido- } \\
\text { sulfatado }\end{array}$ \\
\hline $\begin{array}{l}\text { Epitermales de baja } \\
\text { sulfuración }\end{array}$ & 6.2 & $\begin{array}{l}\text { py, gn, sp, Au / Ag } \\
\text { / electrum, thd }\end{array}$ & $\begin{array}{l}\text { ccp, ht, arg, } \\
\text { seleniuros y } \\
\text { sulfosales de Ag }\end{array}$ & $\begin{array}{l}\text { Creede, Colorado, } \\
\text { EE. UU. } \\
\text { Cabo de Gata } \\
\text { (Almería) }\end{array}$ & $\begin{array}{l}\text { Antes conocidos como tipo } \\
\text { adularia - sericita (F 2) }\end{array}$ \\
\hline $\begin{array}{l}\text { Yacimientos de oro } \\
\text { diseminado tipo Carlin }\end{array}$ & 7 & $\begin{array}{l}\mathrm{Au}, \mathrm{py}, \mathrm{asp}, \\
\text { sulfosales }\end{array}$ & goe, jarosita & $\begin{array}{l}\text { Carlin Trend (Nevada, } \\
\text { EE. UU.) }\end{array}$ & $\begin{array}{l}\text { Oro ultrafino ("invisible"), } \\
\text { diseminado }\end{array}$ \\
\hline $\begin{array}{l}\text { Sulfuros masivos } \\
\text { volcanogénicos (SMV) }\end{array}$ & 8.1 & $\begin{array}{l}\text { py, ccp, sp, po, } \\
\text { gn, thd }\end{array}$ & $\begin{array}{l}\text { bn, Au y Ag nat., } \\
\text { sulfosales, cs, } \\
\text { mar, bm, asp, cc, } \\
\text { cv, dig, goe, ht... }\end{array}$ & $\begin{array}{l}\text { Faja Pirítica Iberica } \\
\text { (Río Tinto, Neves } \\
\text { Corvo, etc.) }\end{array}$ & $\begin{array}{l}\text { Subclases variadas. Posible } \\
\text { enriquecimiento supergénico } \\
\text { (Au / Ag...) (F 6) }\end{array}$ \\
\hline $\begin{array}{l}\text { Formaciones } \\
\text { Bandeadas de Hierro } \\
\text { (Banded Iron } \\
\text { Formations: BIF ) }\end{array}$ & 8.2 & $\mathrm{mg}, \mathrm{ht}$, chert & $\begin{array}{l}\text { siderita, py, } \\
\text { martita, goe }\end{array}$ & $\begin{array}{l}\text { Guayana; Liberia; } \\
\text { Hammersley Basin (W. } \\
\text { Australia); L. Superior } \\
\text { (EE. UU.), }\end{array}$ & $\begin{array}{l}\text { Grandes tonelajes en escudos } \\
\text { precámbricos. Posible } \\
\text { metalotecto Au. (F 5) }\end{array}$ \\
\hline
\end{tabular}


RECONOCIMIENTO AUTOMATIZADO DE MENAS METÁLICAS MEDIANTE ANÁLISIS DIGITAL DE IMAGEN: UN APOYO AL PROCESO MINERALÚRGICO... AUTOMATED MICROSCOPIC CHARACTERIZATION OF METALLIC ORES WITH IMAGE ANALYSIS: A KEY TO IMPROVE ORE PROCESSING...

Tabla V. Asociaciónes mineralógicas (menas más frecuentes) correspondientes a las clases de yacimientos de la Tipología simplificada (Tabla I)

Table V. Mineral Associations (most common ores) related to selected deposit types (Table I)

\begin{tabular}{|c|c|c|c|c|c|}
\hline \multirow[t]{2}{*}{ TIPO DE YACIMIENTO } & \multirow[t]{2}{*}{$\begin{array}{l}\text { CLASE } \\
\text { (Tab.I) }\end{array}$} & $\begin{array}{l}\text { ASOCIACIONES } \\
\text { (MENAS*) }\end{array}$ & MINERALES & \multirow[t]{2}{*}{ EJEMPLOS } & \multirow[t]{2}{*}{ OBSERVACIONES (**) } \\
\hline & & \multicolumn{2}{|c|}{ Mins Principales Mins Accesorios } & & \\
\hline $\begin{array}{l}\text { Yacimientos } \\
\text { estratoligados de Pb, } \\
\mathrm{Zn}, \mathrm{Cu} \text { (Sedex / en r. } \\
\text { carbonatadas / } \\
\text { Kupferschiefer / } \\
\text { Copperbelt) }\end{array}$ & $9.1 / 9.2$ & $g n, s p, c c p, b n, c c$ & $\begin{array}{l}\text { thd / sulfosales, } \\
\text { In, py }\end{array}$ & $\begin{array}{l}\text {-Sedex: Rammelsberg } \\
\text { (Alemania); } \\
\text {-R_Carb: Miss.Valley, } \\
\text { EE. UU.; } \\
\text {-Kupferschiefer: Lubin, } \\
\text { Pol.; Mansfeld, } \\
\text { Alemania; } \\
\text {-Copperbelt: Mufulira } \\
\text { (Zambia), Shaba (RD } \\
\text { Congo) }\end{array}$ & $\begin{array}{l}\text { Menas dominantes: } \\
\text {-Cu / Cu-Co (Copperbelt: } \\
\text { Shaba, RD Congo) } \\
\text {-Pb-Zn (Sedex / Miss. Vall.) }\end{array}$ \\
\hline $\begin{array}{l}\text { Detríticos, placeres y } \\
\text { paleoplaceres }\end{array}$ & 10.1 & $\begin{array}{l}\text { Au, EGP, uran, ru, } \\
\text { cs, il, diamantes, } \\
\text { etc. }\end{array}$ & $\begin{array}{l}\text { ht, mg, columbo- } \\
\text { tantalita, silicatos, } \\
\text { etc. }\end{array}$ & $\begin{array}{l}\text { Malasia (placeres cs), } \\
\text { Witwatersrand, RSA } \\
(\mathrm{Au}, \mathrm{U})\end{array}$ & $\begin{array}{l}\text { Witwatersrand: la mayor } \\
\text { concentración Au del mundo } \\
\text { (meta - conglomerados) }\end{array}$ \\
\hline Lateríticos & 10.2 & $\begin{array}{l}\text { goe, mins. Al / } \mathrm{Ni} \\
\text { residuales: gibbs., } \\
\text { boehm., Ni-nontr., } \\
\text { garnierita, etc. }\end{array}$ & Trazas EGP, Au. & $\begin{array}{l}\text { Lateritas, bauxitas y } \\
\text { lateritas niquelíferas de } \\
\text { Nueva Caledonia, Moa } \\
\text { (Cuba), etc. }\end{array}$ & $\begin{array}{l}\text { Mineralogía poco adecuada } \\
\text { para las técnicas de } \\
\text { microscopía con luz reflejada }\end{array}$ \\
\hline
\end{tabular}

Skarn

11

mg, ccp, wf, po, ht, sulfosales, -Tintaya (Cu-Au) y

Yacimientos y mineralogía scheel, $\mathrm{Au}$, asp,

cs, ht, goe, $\quad$ Pierina (Zn), Perú; muy variados y complejos mo, sp, etc.

silicatos Ca-Mg, -Cala, Badajoz ( $\mathrm{Fe}$,

etc. $\quad \mathrm{Au}$ ); Carlés, Asturias

(Au-Cu)

Yacimientos de oro

12.1

$\mathrm{Au} /$ telururos /

gn, stib, sp, ccp

Val d'Or, Hemlo, etc electrum, py, asp, gra, ru, mo, Quebec, Canadá

po, etc. sulfosales

Sinónimos: greenstone, archaean, shear zone, goldonly, vein type, metamorphic, mesothermal ... gold deposits

Yacimientos 12.2

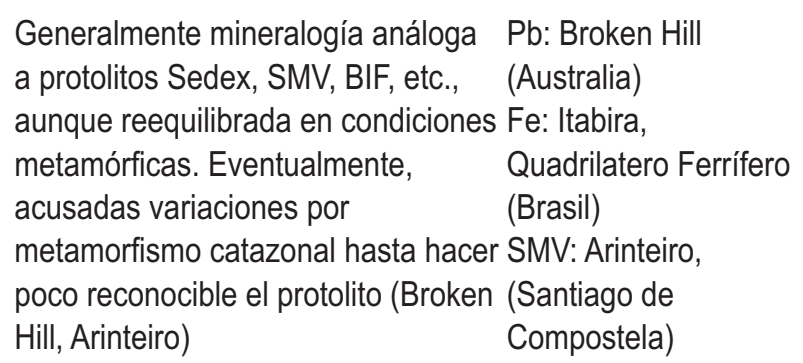
Metamorfismo reconocible por texturas modificadas

metamorfizados y

(") MENAS: por razones de espacio, se representan los minerales por sus símbolos, según las Tablas II, III, IV.

$\left(^{* *}\right)$ OBSERVACIONES: Se indican por su numeración $(\mathrm{F} 1$ a F10) las fotomicrografías que ilustran algunas asociaciones (figuras 1 y 2).

Teniendo en cuenta este análisis, las asociaciones minerales establecidas son una herramienta geológica que puede prestar una ayuda decisiva para garantizar el reconocimiento automatizado basado en los valores de reflectancia medidos ${ }^{[1]}$. Esto se logra por dos vías complementarias:

- reduciendo de entrada el número de especies a considerar; por tanto, disminuyendo la 

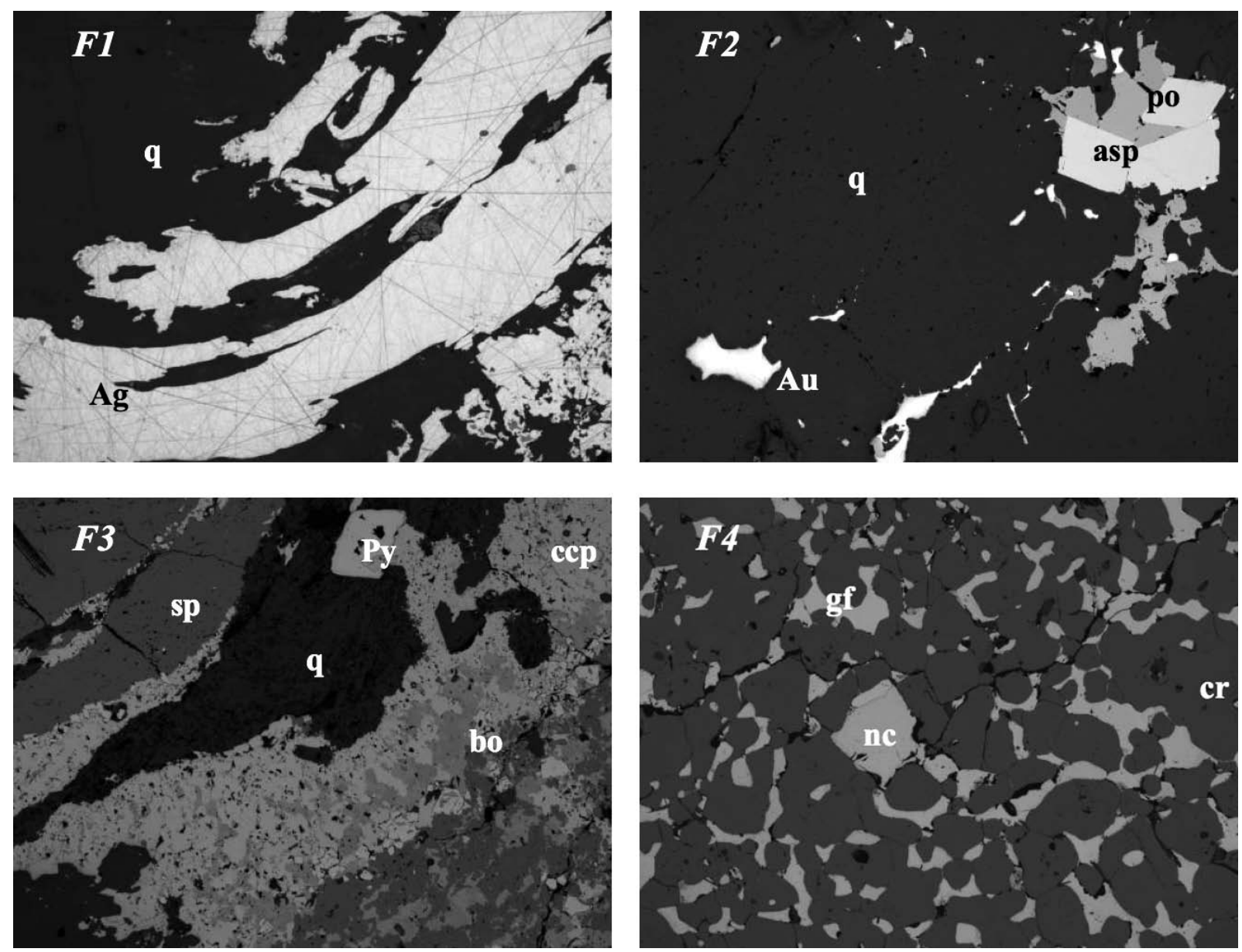

Figura 1. Ejemplos de asociaciones minerales comunes (Tablas I y V). Fotomicrografías F1 a F4, con luz reflejada (en aire, sin analizador). La base de la fotografía corresponde a una longitud real de $2,5 \mathrm{~mm}$.

F1. Plata nativa (Ag). (CR-288: Tipo 4.1). Mina Schneeberg, Alemania (donación Dr. HJ Bernhardt).

F2. Oro nativo ( $A u$ ) en ganga de cuarzo (q), acompañado de pirrotina (po) y arsenopirita (asp). (CR295: Tipo 6.2). Mina La Rinconada, Puno, Perú.

F3. Mena de calcopirita (ccp) y esfalerita (sp), con bournonita (bo) y pirita (py), en ganga de cuarzo (q). (CR-285: Tipo 4.1).

F4. Mena de cromita (cr), con niquelina (nc) y gersdorffita (gf) intersticiales. (C11: Tipo 1.1). Mina Los Jarales, Carratraca, Málaga.

Figure 1. Some examples of common mineral associations in ores (types from Tables I and V). F1 to F4: reflected light photomicrographs (air, plain polarized light). Length of picture: $2,5 \mathrm{~mm}$.

F1. Native silver (Ag). (CR-288: Type 4.1). Mine: Schneeberg, Germany (don. Dr. HJ Bernhardt).

F2. Native gold (Au) in quartz gangue (q), accompanied by pyrrothite (po) and arsenopyrite (asp). (CR-295: Type 6.2). Mine: La Rinconada, Puno, Perú.

F3. Chalcopyrite (ccp) and sphalerite (sp) ore, with bournonita (bo) and pyrite (py), in quartz gangue (q). (CR-285: Type 4.1).

F4. Chromite ore (cr), with interstitial niccolite (nc) and gersdorffite (gf). (C11: Tipo 1.1). Mine: Los Jarales, Carratraca, Málaga.

incertidumbre y el riesgo de error en las identificaciones y aumentando, al mismo tiempo, el rendimiento del proceso: no es lo mismo elegir entre 10 o 15 minerales que entre varios cientos;
- aportando criterios de decisión complementarios, con la ventaja añadida de que son externos al proceso de medida y, por tanto, independientes de posibles sesgos experimentales o errores del sistema. 

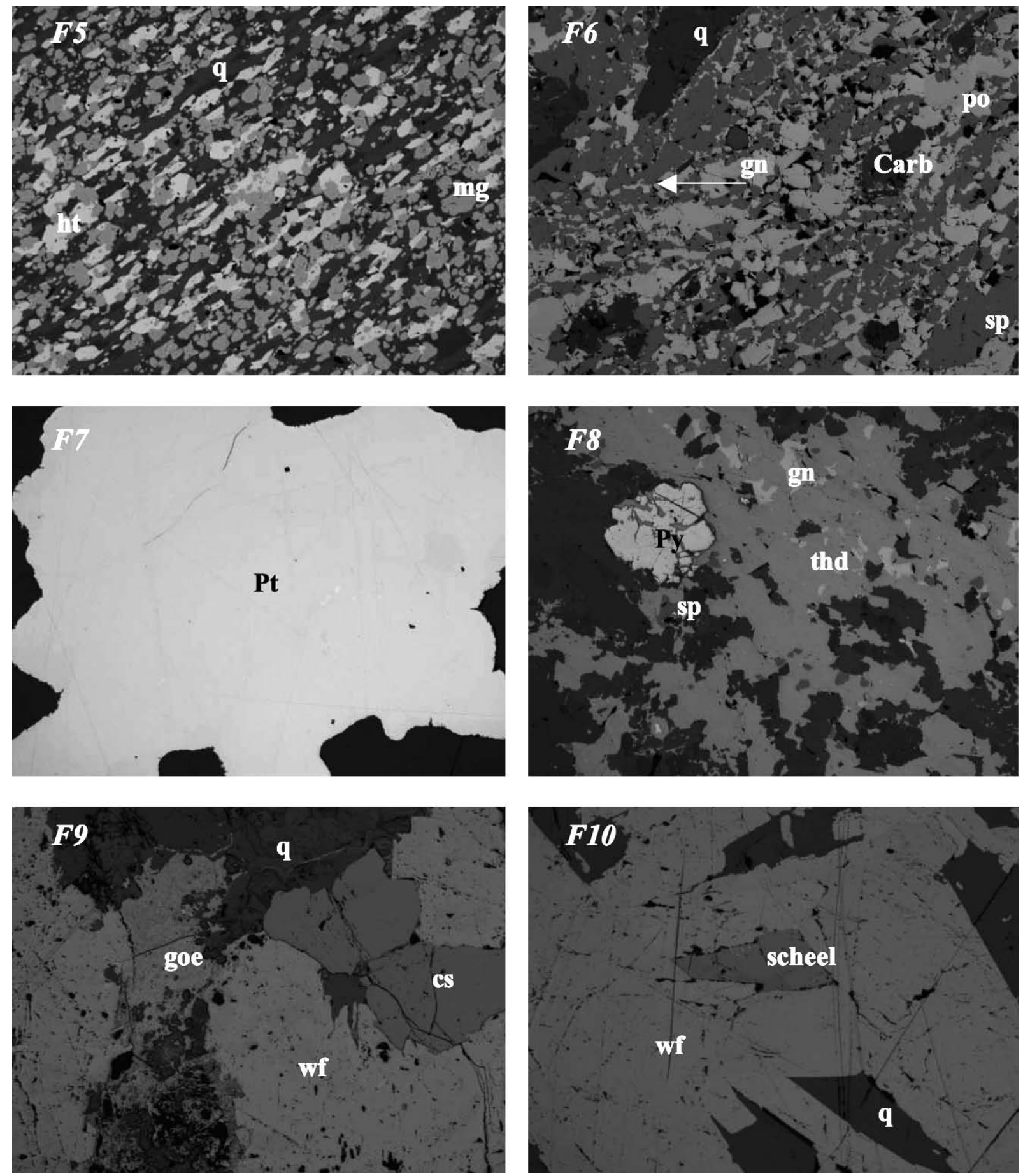

Figura 2. Ejemplos de asociaciones minerales comunes (Tablas I y V). Fotomicrografías F5 a F10, con luz reflejada (en aire, sin analizador). La base de la fotografía corresponde a una longitud real de $2,5 \mathrm{~mm}$.

F5. Mena de magnetita (mg) y hematites (ht) en ganga de cuarzo (q). (CR-280: Tipo 8.2). Mcllwaine Pk., Harare, Zimbabwe.

F6. Asociación de pirrotita (po) y esfalerita (sp), con galena intersticial (gn) y ganga de cuarzo (q) y carbonato (Carb). (CR-270: Tipo 8.1). Mina Sullivan, BC Canada

F7. Platino nativo (Pt) aluvionar. (CR-298: Tipo 1.3). Nizhne, Taguilsk (Urales, donación J. Proenza).

F8. Tetrahedrita masiva (thd), con inclusiones de pirita (py), galena (gn) y esfalerita (sp). (CR-266c: Tipo 4.1). Mina Lucky Friday, Coeur d'Alène (Idaho, USA).

F9. Relleno filoniano de wolframita (wf), con inclusiones de casiterita (cs) y goethita (goe), en ganga cuarzosa (q). (CR-301: Tipo 3.1). Mina Beariz, Orense.

F10. Mena de wolframita (wf), en agregados de cristales prismáticos con inclusiones intersticiales de scheelita (scheel) y cuarzo (q). (CR-274: Tipo 3.2). Mina Monteneme, Coruña. 
Figure 2. Some examples of common mineral associations in ores (types from Tables I and V). F5 to F10: reflected light photomicrographs (air, plain polarized light). Length of picture: 2,5 $\mathrm{mm}$.

F5. Magnetite (mg) and hematite (ht) ore ) in quartz gangue (q). (CR-280: Type 8.2). Mcllwaine Pk., Harare, Zimbabwe.

F6. Pyrrothite (po) and sphalerite (sp) association, with interstitial galena (gn) and quartz (q) \& carbonate (Carb) gangue. (CR-270: Type 8.1). Mine: Sullivan, BC_Canada

F7. Native platinum (Pt). (CR-298: alluvial deposit, from Type 1.3). Nizhne, Taguilsk (Urals, don. J. Proenza).

F8. Massive tetrahedrite (thd), with pyrite (py), galena (gn) and sphalerite (sp) inclusions. (CR-266c: Type 4.1). Mine: Lucky Friday, Coeur d'Alène (Idaho, USA).

F9. Vein infill of wolframite (wf), with cassiterite (cs) and goethita (goe) inclusions, in quartz gangue (q). (CR-301: Type 3.1). Mine: Beariz, Orense (Spain).

F10. Wolframite - scheelite association: prismatic crystals of wolframite (wf) in aggregates, with inclusions of scheelite (scheel) and quartz (q). (CR-274: Type 3.2). Mine: Monteneme, Coruña (Spain).

\subsection{Discusión}

Tal como se puso de manifiesto en la validación del proceso experimental ${ }^{[1]}$, las menas metálicas más comunes pueden identificarse, habitualmente, de forma automatizada por sus valores de reflectancia, si dicho proceso se hace en las condiciones de rigor y precisión requeridas (el proceso puede mejorarse, todavía, introduciendo técnicas de última genera-

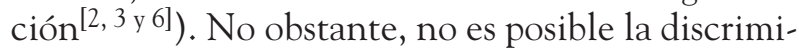
nación entre minerales de espectros idénticos o muy próximos.

Para arrojar luz sobre los riesgos de confusión o incertidumbre, se elaboró, para cada una de las asociaciones minerales correspondientes a la tipología simplificada (Tablas I y V), una relación de minerales agrupados por sus propiedades de reflectancia ${ }^{[1]}$. De esta forma, antes de comenzar el trabajo, el operador dispone de una información inmediata y directa de la eventual incertidumbre. Esta incertidumbre ha quedado ya, de todas formas, muy reducida porque, al introducir como filtro la asociación mineral correspondiente al tipo de yacimiento (y previamente comprobada al microscopio por el operador), se descartan automáticamente un número importante de opciones y, por tanto, de posibles confusiones.

No obstante, si entre las opciones de la asociación mineral objeto de estudio hubiese riesgo de indeterminación, éste queda patente por la proximidad de los espectros y su conocimiento (previo) permite al operador tomar las medidas correspondientes. Por ejemplo, evaluar los resultados posibles en función de las necesidades de información para la planta de tratamiento. Habitualmente, las ambigüedades afectan a minerales cuya presencia es anecdótica (trazas) o cuya discriminación es irrelevante para el proceso mineralúrgico (como pirita y marcasita), pero si existiesen minerales de reflectancias similares cuya discriminación fuese necesaria, el operador estaría en condiciones de anticiparse al problema y decidir el criterio a aplicar y la forma de hacerlo (El trabajar con información digitalizada tiene la ventaja de per- mitir una gran versatilidad a la hora de introducir nuevos criterios, por ejemplo, análisis químicos que pueden recalcularse a composiciones modales y que aportan una discriminación objetiva y cuantificada en cifras directamente comparables a las determinadas por ADI y que, por tanto, pueden utilizarse como referencia o factor de corrección $\left.{ }^{[6]}\right)$. Así, puede evitar un trabajo cuyos resultados vayan a ser previsiblemente irrelevantes o bien puede tomar a tiempo las medidas oportunas para completar la información que el caso requiera, a fin de dar respuesta a las demandas del mineralurgista.

\subsection{Ejemplos de aplicación}

Como ejemplo, se reproduce y aplica esta caracterización cuantificada de las asociaciones minerales, basada en el cálculo de valores medios de reflectancia con luz blanca, para las menas de algunos tipos (Tabla VI), cuyas posibilidades de discriminación fiable serán analizadas a la luz de esta información. Para otras asociaciones y yacimientos, la relación puede completarse en la fuente citada ${ }^{[1]}$.

En el caso de los yacimientos asociados a rocas ultramáficas y a complejos ofiolíticos (clases $1.1 \mathrm{a}$ 1.4: tabla I; primer grupo: tabla VI), la discriminación por $\mathrm{ADI}$ es, en principio, poco problemática, teniendo en cuenta la naturaleza de las principales menas beneficiadas: cromita; EGP (Pt y MGP, Minerales del Grupo del Platino); sulfuros de $\mathrm{Ni}-\mathrm{Cu}$ (pentlandita, calcopirita); óxidos Fe-Ti: magnetita, titano-magnetita e ilmenita; sulfuros masivos (ofiolíticos) \pm oro. En efecto, los metales preciosos y los MGP se diferencian claramente, por sus valores elevados de reflectancia ( $>60 \%$, excepto contados casos de compuestos de Au o EGP), de todos los demás. Por el contrario, la otra mena más típica del grupo, la cromita, se encuentra en el extremo opuesto de los valores de reflectancia, el más bajo, pero con un valor $(12,5 \%)$ que permite distinguirla 
RECONOCIMIENTO AUTOMATIZADO DE MENAS METÁLICAS MEDIANTE ANÁLISIS DIGITAL DE IMAGEN: UN APOYO AL PROCESO MINERALÚRGICO... AUTOMATED MICROSCOPIC CHARACTERIZATION OF METALLIC ORES WITH IMAGE ANALYSIS: A KEY TO IMPROVE ORE PROCESSING...

Tabla VI. Ejemplos de discriminación por reflectancias de los componentes de asociaciones minerales tipológicas $\left(^{*}\right)$

Table VI. Mineral discrimination in ore associations of some deposit types based on mean reflectance values in white light

\section{En rocas Ultramáficas y Complejos Ofiolíticos}

1. Oro (72), EGP (65).

2. Arsenopirita (52), Pirita (51), Pentlandita (49), Niquelina (50,5-45), Calcopirita (45),

3. Pirrotina (39)

4. Martita (29), Hematites (29), Rutilo $(23,5)$,

5. IImenita (19,5), Esfalerita (19), Magnetita (17), Cromita (12,5), Espinela (8)

6. Ganga (6).

\section{Pegmatítico** -Neumatolíticos}

1. Oro (72), Bismuto (67).

Fases Sulfuradas

2. Arsenopirita (52), Pirita (51), Calcopirita (45), Molibdenita (42-19), Galena (43), Estannita (28), Pirrotina (39).

Fases Oxidadas

3. Rutilo $(23,5)$.

4. Wolframita (17), Casiterita (13), Scheelita (11).

Silicatos

Berilo (5), Turmalina (6), Mica (5), Cuarzo (5).

**Las pegmatitas complejas (minerales de TR, gemas, piedras semi-preciosas, etc.) exigen tratamiento individualizado.

\section{Hidrotermales $\mathrm{Pb}-\mathrm{Zn}-\mathrm{Ag}$}

1. Plata (85), Electrum (80).

2. Arsenopirita (52), Pirita (51).

3. Calcopirita (45), Galena (43).

4. Bournonita (36), Argentita (32), Tetrahedrita (31) y otras sulfosales.

5. Esfalerita (19).

6. Ganga (6)

\section{Sulfuros masivos volcano - sedimentarios (SMV)}

1. Plata (85), Electrum(80), Oro (72),

2. Arsenopirita (52), Pirita (51), Arseniuros Blancos (51).

3. Calcopirita (45), Galena (43), Pirrotina (39).

4. Hematites (29), Rutilo (23,5), Magnetita (17).

5. Goethita(18 - 15), Casiterita (13), Jarosita (7).

\section{En Terrenos Metamórficos: Yacimientos de oro orogénicos:}

1. Electrum (80), Oro (72).

2. Arsenopirita (52), Pirita (51).

3. Calcopirita (45)

4. Galena (43), Estibinita (47-30), Molibdenita (42-19), Pirrotina (39).

5. Hematites (29), Rutilo $(23,5)$.

6. Esfalerita (19), Grafito (16-6).

7. Ganga (6).

$\left(^{*}\right)$ Los valores medios de reflectancia ( $\mathrm{R} \%$ ), calculados en luz blanca, se indican entre paréntesis tras el nombre del mineral y permiten agrupar las menas en categorías, según sus rangos; éstos proporcionan una primera indicación sobre las diferencias espectrales. Se destacan en negrita los minerales importantes en cada tipo; éstos no siempre son los más frecuentes. 
sin dificultad de los otros términos del grupo de las espinelas (magnetita, $17 \%$, y espinela s.str., $8 \%$ ). Por su parte, los demás óxidos (hematites / martita a magnetita) tienen valores suficientemente distantes $(29$ a $17 \%)$ para asegurar su discriminación entre sí; más todavía, con los sulfuros (>39 \%), aun reconociendo la proximidad entre esfalerita $(19 \%)$ e ilmenita $(19,5 \%)$ o incluso magnetita (17\%); no obstante, el análisis de las asociaciones reales (Tabla V) indica que, habitualmente, la esfalerita no coexistirá con dichos óxidos, ya que se presentan en clases de yacimientos diferentes (sulfuros masivos volcanogénicos y yacimientos de óxidos $\mathrm{Fe}-\mathrm{Ti}$, respectivamente). Finalmente, la principal mena sulfurada de este grupo (calcopirita en sulfuros masivos volcanogénicos), se distingue sin dificultad de sus acompañantes en esta clase (pirita, pirrotita, etc.) y lo mismo ocurre con pentlandita y niquelina, en la clase de los sulfuros de $\mathrm{Ni}$ - $\mathrm{Cu}$, pues aunque tengan valores medios de reflectancia relativamente próximos su color y, por tanto, sus valores espectrales los diferencian.

Las asociaciones pegmatítico-neumatolíticas (Tabla VI) tampoco plantean dificultades de discriminación ya que la mayor parte de las menas útiles se caracterizan por valores diferenciados de reflectancia, aunque ha de reconocerse que hay componentes, sobre todo en las pegmatitas complejas, que se estudian mejor con luz transmitida y, por tanto, están fuera del ámbito de aplicación de las técnicas ahora discutidas. Sin embargo, la casiterita y la scheelita (lo mismo que el rutilo o el término manganifero de la wolframita, la huebnerita) pueden identificarse tanto por transmisión como por reflexión y, en este último caso, sus valores de reflectancia ( 13 y $11 \%$, respectivamente) próximos a los de cromita (12'5\%) podrían inducir a confusión con esta mena, pero el análisis de las asociaciones minerales respectivas muestra que no se presentan juntas y, por tanto, descarta el error.

Las asociaciones hidrotermales y volcano-sedimentarias (a continuación, en la tabla VI; clases 4 y 8.1 en la tabla I) comparten algunas características esenciales. Las menas principales (metales preciosos, sulfuros $\mathrm{Pb}-\mathrm{Zn}-\mathrm{Cu}$ o galena, esfalerita, calcopirita, considerando también sus derivados en zona de cementación: calcocita, covellina, digenita, principalmente) pueden discriminarse sin dificultad en condiciones normales, aunque, en algunos casos, la granulometría muy fina y los intercrecimientos complejos pueden desafiar la capacidad de resolución del microscopio óptico (se trata, en estos casos, de una limitación instrumental, no de la metodología ADI). La casiterita, que puede ser un componente económicamente importante de los sulfuros masivos (como ocurre en el gran yacimiento de Neves Corvo, Portugal), se caracteriza sin dificultad, en esta asociación, por su baja reflectancia, inferior también a la de las paragénesis secundarias de oxidación supergé- nica (goethita, hematites), que pueden superponerse a los sulfuros o incluso llegar a ser dominantes en algunas zonas (gossan). No obstante, en ambas asociaciones algunas sulfosales muy minoritarias (y, por ello, no detalladas en la tabla IV) pueden tener rangos de reflectancia parecidos (habitualmente, entre 30 y $36 \%$ ) que arrojan incertidumbre sobre su discriminación, pero dada su escasa importancia cuantitativa y económica, suele ser suficiente, en estos casos, el identificarlas todas como un solo grupo, obteniéndose así una estimación de conjunto para elementos minoritarios ( $\mathrm{Sb}, \mathrm{As}, \mathrm{Bi}$, etc.) cuyo margen de error no tiene por qué superar el inherente a la representatividad de la muestra con respecto al yacimiento $^{[32]}$.

Finalmente, pasando a tipos metamórficos, los yacimientos de oro orogénicos (último grupo de la tabla VI, clase 12.1 en la tabla I), también conocidos como gold-only deposits por ser el oro la única mena beneficiada, representan realmente un reto muy fácil, en principio, desde el punto de vista de la segmentación de la mena, a pesar de su complejidad mineralógica y textural y de las dificultades que entraña su exploración. En efecto, las fases interesantes para el metalurgista (oro, electrum) se discriminan con valores de reflectancia $>70 \%$, no alcanzados por ningún otro de sus acompañantes ${ }^{[33]}$, si bien, ocasionalmente, la existencia de otros portadores de oro posibles (telururos, sulfuros o arseniuros con oro diseminado en la red cristalina, es decir, no expresado mineralógicamente, etc.) puede demandar un estudio más exigente. Por otra parte, los valores de reflectancia calculados (Tabla VI) sugieren que la mayor parte de los componentes típicos de esta asociación podrían discriminarse sin dificultad.

Esta breve discusión de las asociaciones reales pone de manifiesto que su análisis por un profesional experimentado puede proporcionar una herramienta decisiva, por su eficacia para mejorar el rendimiento y reducir la incertidumbre del reconocimiento automatizado para el estudio por ADI.

\section{CONCLUSIONES Y APLICACIONES}

El reconocimiento automatizado de menas metálicas es posible a través de las medidas de reflectancia por medio de microscopio de reflexión provisto de una cámara de investigación color 3CCD y una tarjeta de adquisición para producir imágenes digitales en condiciones prefijadas ${ }^{[1]}$, así como también mediante técnicas multiespectrales ${ }^{[2 \text { y } 3]}$. Esta metodología, basada en la reflectancia especular medida en condiciones particulares ( $\sin$ polarizadores), está sometida inevitablemente a las limitaciones implícitas en el recurso a una sola propiedad física medida: algunas menas me- 
tálicas pueden tener valores similares y, en esos casos, la identificación puede ser ambigua.

No obstante, en los casos comunes, esto ocurre pocas veces y la ambigüedad puede superarse recurriendo a criterios externos. Entre éstos, los de tipo geológico son los más inmediatos y eficaces, al ofrecer filtros selectivos que permiten el tratamiento categorizado de la información espectral obtenida.

El primero es la limitación de errores, mediante la definición previa de las menas más comunes y frecuentes de interés industrial, que representan la inmensa mayor parte de los casos sometidos a estudio habitualmente y que son sólo una pequeña fracción de las existentes: aunque podrían reducirse a una treintena, se ha establecido una relación prioritaria de 38 especies (Tabla II; los minerales de ganga, como cuarzo o carbonatos, aunque pueden identificarse de una manera general, requieren en principio el recurso a otras técnicas: luz transmitida). No son éstos los únicos minerales que pueden identificarse, pero es conveniente limitar los criterios de busca por razones prácticas (rendimiento y acotación de errores); las tablas III y IV presentan minerales que, si bien no son precisamente comunes, deben considerarse en determinados casos. La documentación o la observación previa por un mineralogista experto deben indicar la opción preferente, que será casi siempre la más general (Tabla II).

La agrupación de minerales según sus asociaciones naturales, fruto de un análisis tipológico de yacimientos comunes y de sus correspondientes paragénesis, es otro filtro importante. Efectivamente, los minerales no se encuentran distribuidos al azar en cualquier yacimiento, sino que su presencia muestra unas regularidades que los metalogenistas conocen y que permiten introducir en el sistema criterios de busca muy útiles, evitando asociaciones imposibles o cuestionando las improbables. Las tablas I y V ofrecen esta información.

La efectividad de este análisis puede examinarse comparando los datos ofrecidos en la tabla VI, en la que se ve que los principales minerales de cada asociación pueden distinguirse habitualmente sin dificultad por sus valores de reflectancia y, en cambio, hay minerales con valores espectrofotométricos parecidos, como cromita y casiterita, que no se confundirán en la realidad porque no se generan juntos sino en ámbitos diferentes (por ejemplo: pegmatítico-neumatolíticos o de sulfuros masivos, la casiterita; ultramáficos, la cromita).

En conclusión, el análisis digital de imagen, ADI, acoplado al microscopio óptico de reflexión ofrece un instrumento poderoso, eficaz y relativamente muy económico (si se compara con el coste de inversión y operativo de la microscopía electrónica) para poner la información mineralógica al alcance del metalurgista, siempre que se cumplan tres condiciones:

- debe seguirse un procedimiento riguroso, $\mathrm{Co}$ mo el descrito ${ }^{[1]}$, que garantice la reproducibilidad y la representatividad de las medidas;
- no debe recurrirse al ADI para reemplazar al experto en mineralogía, sino para potenciar sus aportaciones y su rendimiento y esto se consigue en una enorme medida;

- los criterios de segmentación basados en valores físicos (reflectancias) deben ser complementados con criterios de índole geológica (mineralógica o metalogenética), tanto para acotar los errores posibles como para mejorar el rendimiento reduciendo las opciones de busca.

Este recurso complementario a criterios geológi$\cos /$ mineralógicos debe aplicarse incluso con los sistemas de más reciente desarrollo, como los que trabajan con valores multiespectrales VNIR (es decir, en los rangos visible e infrarrojo cercano ${ }^{[2-4]}$, pues como validación externa conservan siempre todo su valor y aportan las mismas ventajas, aunque la metodología de medida sea más avanzada.

\section{Agradecimientos}

El trabajo experimental se realizó en el Laboratorio de Microscopía Aplicada y Análisis de Imagen (Red de Laboratorios de la Comunidad de Madrid: rla 207), Escuela Técnica Superior de Ingenieros de Minas, Universidad Politécnica de Madrid, y cuenta con aportaciones de la tesis doctoral de Edgar Raúl Berrezueta Alvarado. La instrumentación fue co-financiada con ayuda de los proyectos GR-92-0135, UE95-007, UE98-0027 y CGL2006-13688-C02-01 del Ministerio de Educación y Ciencia.

\section{REFERENCIAS}

[1] E. Berrezueta y R. Castroviejo. Rev. Metal. Madrid 43 (2007) 294-309.

[2] E. Pirard, H.J. Bernhardt, J.C. Catalina, C. Brea, F Segundo y R. Castroviejo. $9^{\text {th }}$. Int. Cong.Appl. Mineralogy, Brisbane, QLD, Australia, 2008. Ed. International Mineralogical Association, Commission on Applied Mineralogy (IMA/ CAM), Brisbane, Australia, 2008, pp. 1-6.

[3] R. Castroviejo, J.C. Catalina, H.J. Bernhardt, J.A. Espí, E. Pirard, J Samper J.C. Brea, F. Segundo, J. Locutura, 1. Pérez-Barnuevo, 1. Sánchez y A. Hidalgo, XIII Cong. Latinoam. Geología, Lima, Perú, 2008, J. Arce, E. Ferrari, S. Rosas y H. Tanabe (Eds.), Soc. Geológica del Perú, Lima, Perú, 2008, CD-Rom, Sesión R8.

[4] J.C. Catalina, F. Segundo, G. Fernández y D. Alarcón, XIII Cong. Latinoam. Geología, Lima, Perú, 2008, J. Arce, E. Ferrari, S. Rosas y H. Tanabe (Eds.), Soc. Geológica del Perú, Lima, Perú, 2008, CD-ROM, Sesión R3. 
[5]. E. Berrezueta. Tesis Doctoral. Escuela Técnica Superior de Ingenieros de Minas, Universidad Politécnica de Madrid, 2004.

[6] L. Pérez-Barnuevo, R. Castroviejo y E. Berrezueta. XIII Cong. Latinoam. Geología, Lima, Perú, 2008, J. Arce, E. Ferrari, S. Rosas y H. Tanabe (Eds.), Soc. Geológica del Perú, Lima, Perú, 2008, CD-ROM / Sesión R5.

[7] R. Castroviejo, Introducción al Estudio de los Recursos Minerales, Red DESIR, Universidad Politécnica de Madrid, Madrid, España, 2007, pp. 19-24.

[8] H. Schneiderhoehn, Erzlagersttaetten, FischerVerlag, 4e. Auflage. Stuttgart, Alemania, 1962, pp. 1-371.

[9] I. Robb, Introduction to Ore-Forming Processes, Blackwell Publ, London, 1st. Ed. 2005, pp. 8-11.

[10] H.G.F. Winkler, Petrogénesis de Rocas Metamórficas, $1^{\underline{a}}$ ed. H. Blume, Madrid, España, pp. 1-346.

[11]. A.J. Criddle, Ore microscopy and photometry. L. Cabri and D.J. Vaughan., Eds. Modern Approaches to Ore and Environmental Mineralogy. MAC Short Course v. 27, Mineralogical Association of Canada, Ottawa, Canada, 1998, pp. 1-74.

[12]. H. Schneiderhöhn, Erzmikroskopisches Praktikum, Schweizerbart, $1^{\underline{a}}$ ed., Stuttgart, Alemania, 1952, pp. 1-274.

[13]. P. Ramdohr, The ore minerals and their intergrowths, 2nd Ed., Pergamon, Oxford, Reino Unido, 2 vols, 1980, pp. 1-1205.

[14]. C. Schouten, Determination tables for ore microscopy, Elsevier, Amsterdam, Holanda, 1962, pp. 1242.

[15]. W. Uytenbogaard y E.A.J. Burke, Tables for microscopic identification of ore minerals (2nd. Ed.), Elsevier, Amsterdam, Holanda, 1971, pp. 1-430.

[16]. M. Tarkian, Miner. Sci. Eng. 6 (1974) 101-105.

[17]. P. Picot y Z. Johan, Atlas of ore minerals, Bur. Rech. Geol. Minières, 1st English ed. BRGM, Orleans, Francia, 1982, pp. 1-458.

[18] P.G. Spry y B.L. Gedlinske, Tables for the Determination of Common Opaque Minerals, Economic Geology Publ. Co., El Paso, Texas, EE. UU., 1987, pp. 1-52.

[19] T. Febrel, Microscopía de minerales opacos, ETSI Minas, $1^{\underline{a}}$ ed., Madrid, España, 1970, pp. 1-2.

[20]. J.L. Jambor y D.J. Vaughan (Eds.) Advanced microscopic studies of ore minerals, Min. Association of Canada, Short Course Hdbk. 17, Ottawa, Canada, 1990, pp. 1-357.

[21]. L.J. Cabri y D. Vaughan, Modern approaches to ore and environmental mineralogy, Commission on Ore Mineralogy, International Mineralogical Association (COM/ IMA), Short Course Series., vol. 27, Ottawa, Canada, 1998, pp. 1-459.

[22]. H.J. Bernhardt, Advanced microscopic studies of ore minerals (J. L. Jambor, D. J. Vaughan, eds.), Min. Association of Canada, Short Course Hdbk. 17, Ottawa, Canada, 1990, pp. 189-211.

[23]. S.H.U. Bowie y P.R. Simpson, The Bowie-Simpson system for the microscopic determination of ore minerals, Applied Mineralogy Group of the Mineralogical Society, McCrone Research Assiociates, $1^{\text {st }}$. Students Issue., Londres, Reino Unido, 1980, pp 13-14.

[24] R.W. Le Maitre, Igneous rocks: a classification and glossary of terms, 2nd. Ed. Cambridge Univ. Press, New York, EE. UU., pp. 1-236.

[25] P. Laznicka, Giant metallic deposits - future sources of industrial metals, Springer, Berlin, Alemania, 2006, pp. 1-732p.

[26]. P.R. Ineson, Introduction to practical ore microscopy, Longman, Londres, Reino Unido, 1989, pp. 149-166.

[27]. J.R. Craig y D. Vaughan, Ore microscopy and ore petrography, J. Wiley \& Sons, New York, EE. UU., 1981, pp. 233-287.

[28] R. Edwards y K. Atkinson, Ore deposit geology, Chapman, London, Reino Unido,1986, pp. 1379.

[29]. D. Vaughan, Advanced microscopic studies of ore minerals (J. L. Jambor, D. J. Vaughan, eds.), Min. Association of Canada, Short Course Hdbk. 17, Ottawa, Canada, 1990, p. 85.

[30] R Castroviejo, Complejos ofiolíticos en Iberoamérica, Eds. E.S. Pereira, R. Castroviejo y F. Ortiz, Proyecto XIII.1-CYTED, Madrid, España, pp. 25-70.

[31] P. Heald, N.K. Foley y D.O. Hayba, Economic Geology 82, 1, pp. 1-26.

[32]. R. Castroviejo, E. Chacón, C. Múzquiz y S. Tarquini. Geovision 99, Int. Symp. on Imaging Applications in Geology. Proc., Liège, Bélgica, 1999, E. Pirard (Ed.), Université de Liège, Lieja, Bélgica, 1999, pp. 37-40.

[33] R Castroviejo, E. Berrezueta y R. Lastra. Miner. Metall. Process. J. 19 (2002), 102-109. 